\title{
Can Patients with Left Main Coronary Artery Disease Wait for Myocardial Revascularization Surgery?
}

\author{
Antônio Sérgio Cordeiro da Rocha, Paulo Roberto Dutra da Silva
}

Rio de Janeiro, RJ - Brazil

\begin{abstract}
Objective - To assess the occurrence of cardiac events in patients diagnosed with left main coronary artery disease on diagnostic cardiac catheterization and waiting for myocardial revascularization surgery.
\end{abstract}

Methods - All patients diagnosed with left main coronary artery disease (stenosis $\geq 50 \%$ ) consecutively identified on diagnostic cardiac catheterization during an 8month period were selected for the study. The group comprised 56 patients ( 40 males and 16 females) with a mean age of $61 \pm 10$ years. The cardiac events included death, nonfatal acute myocardial infarction, acute left ventricular failure, unstable angina, and emergency surgery.

Results - While waiting for surgery, patients experienced the following cardiac events: 7 acute myocardial infarctions and 1 death. All events occurred within the first 60 days after the diagnostic cardiac catheterization. More patients, whose indication for diagnostic cardiac catheterization was unstable angina, experienced events as compared with those with other indications $[p=0.03$, relative $\operatorname{risk}(R R)=5.25,95 \%$ confidence interval $=1.47-18.7]$. In the multivariate analysis of logistic regression, unstable angina was also the only factor that independently contributed to a greater number of events $(p=0.02, O R=$ $8.43,95 \% C I=1.37-51.7)$.

Conclusion - Unstable angina in patients with left main coronary artery disease acts as a high risk factor for cardiac events, emergency surgery being recommended in these cases.

Keywords: left main coronary artery disease, surgical indication, cinecoronary arteriography

Instituto Nacional de Cardiologia Laranjeiras - Ministério da Saúde - Rio de Janeiro Mailing address: Antônio Sérgio Cordeiro da Rocha - Rua Roberto Dias Lopes, 220/201 - 22010-110 - Rio de Janeiro, RJ, Brazil - E-mail: ascrocha@cardiol.br English version by Stela Maris C. e Gandour
Several studies have identified left main coronary artery disease as an independent factor of greater morbidity and mortality after myocardial revascularization surgery ${ }^{1-3}$. The lesions of the left main coronary artery $>50 \%$ are one of the anatomical indications for myocardial revascularization surgery ${ }^{1}$. Both the CASS ${ }^{4}$ and VACS ${ }^{5}$ studies have shown that myocardial revascularization surgery prolongs the life of individuals with left main coronary artery disease; however, in the VACS ${ }^{5,6}$ study the benefit provided by myocardial revascularization surgery as compared with clinical treatment was only evident 3 months after surgery. Despite this evidence, the indication of emergency surgery after identifying that condition, independently of the patients' symptoms, has been established among clinicians and surgeons. Considering the difficulty in providing myocardial revascularization surgery in the integrated hospitals of the Brazilian public health system (SUS), especially in the referral hospitals for these procedures, and considering the necessity to provide emergency myocardial revascularization surgery to patients with left main coronary artery disease, we decided to investigate what happened to these patients after the identification of the coronary lesions on diagnostic cardiac catheterization at a referral hospital for myocardial revascularization surgery.

\section{Methods}

We carried out an observational retrospective study of all patients with left main coronary artery disease consecutively identified on diagnostic cardiac catheterization during an 8-month period. Left main coronary artery disease was considered present when an obstruction of the vessel lumen $\geq 50 \%$ occurred. From the time of the identification of the lesion in the left main coronary artery onward, and whenever possible, the patients remained hospitalized to undergo emergency myocardial revascularization surgery. All patients, except one, underwent myocardial revascularization surgery. However, this surgery was not performed on an emergency basis (during the same period of hospitalization) in many patients due to 1 death and to several factors 
related to the patients' preparation for surgery, to the reluctance of some patients to undergo the procedure, and to logistical problems regarding the implementation of the procedure. The mean time elapsed between cardiac catheterization and myocardial revascularization surgery was $69 \pm 68$ days, ranging from 4 to 352 days. The group comprised 56 patients ( 40 males and 16 females) with a mean age of $61 \pm 10$ years, ranging from 39 to 78 years.

The cinecoronary arteriographies were performed according to the techniques of Sones and Shirley ${ }^{7}$ or Judkins ${ }^{8}$ using adequate views to better visualize the arterial obstructions.

Cinecoronary arteriography in the presence of a left main coronary artery lesion is a procedure with a high risk of complication $^{9-11}$; however, no complication was observed in the population studied.

Cardiac catheterization was required for 1 of the following reasons: a) decision of the assisting physician, independently of the symptoms or presence of ischemia or ventricular dysfunction - 15 cases (including 6 patients after the acute phase of myocardial infarction); b) functional class $\geq$ II stable angina according to the Canadian Cardiovascular Society (CCS), despite adequate antiischemic medication - 10 cases; c) positive (symptom-limiting) exercise test -20 cases; d) presence of left ventricular dysfunction, confirmed by the presence of the third cardiac sound on cardiac auscultation or a left ventricular shortening fraction $<25 \%$ on the 2-dimensional echocardiogram, or both -3 cases; e) investigation after resuscitation from cardiopulmonary arrest - 1 case; and f) unstable angina (all patients were stabilized after adequate medication) - 7 cases.

Urgent surgery was considered that performed during the same hospitalization for cardiac catheterization, and emergency surgery was that performed within a few hours to avoid morbidity or death. Stable angina was functionally diagnosed according to the criteria of the Canadian Cardiovascular Society, and unstable angina was classified according to the criteria proposed by Braunwald ${ }^{12}$.

The following data were collected: a) demographic data, risk factors for coronary atherosclerosis (arterial hypertension, smoking, dyslipidemia, diabetes, familial history of coronary artery disease), and risk factors for myocardial revascularization surgery (age $>70$ years, female sex, ejection fraction $<40 \%$, emergency surgery, previous myocardial revascularization surgery, peripheral vascular disease, cerebrovascular disease, chronic renal failure, chronic obstructive pulmonary disease $)^{3}$; b) the degree of obstruction of the left main coronary artery (subjective assessment), arterial dominance, and lesions in other arteries; c) cavitary diameters and left ventricular shortening fraction obtained on 2-dimensional echocardiography; d) the reason for indicating cardiac catheterization (see above): based on information contained in the medical records or collected directly with the patients or their respective assistant physicians; e) the time interval between cardiac catheterization and myocardial revascularization surgery; f) cardiac events: acute left ventricular failure, complex ventricular arrhythmias requiring hospitalization or cardioversion, acute myocardial infarction, need for emergency surgery, or cardiac death.

The mean degree of obstruction of the left main coronary artery was $74 \pm 16 \%$, ranging from 50 to $99 \%$.

For the statistical analysis, SPSS 8.0 statistical software for Windows was used. The Student $t$ test or the analysis of variance (ANOVA) was used for comparing the continuous variables. For comparing the categorical variables, the chi-square test or the Fisher exact test was used, and for linear correlations, the Pearson test was used. To determine the factors independently influencing the appearance of cardiac events, while the patients waited for surgery, the multivariate analysis of logistic regression (forward) was used. The significance level adopted was $\mathrm{p} \leq 5 \%$.

\section{Results}

While the patients waited for surgery, 7 acute myocardial (6 Q-wave and 1 non-Q-wave) infarctions occurred. One acute myocardial infarction was fatal, occurring 4 days after catheterization. The other acute myocardial infarctions occurred within a 30-day median. All events appeared within the first 60 days following cardiac catheterization, and 5 occurred in the first 30 days. No statistically significant difference was observed between the patients who experienced the events and those who did not experience them, in regard to age, sex, risk factors for atherosclerosis and for revascularization surgery, ventricular function, degree of obstruction of the left main coronary artery disease, involvement of other arteries, in addition to that of the left main coronary artery, or arterial dominance (tab. I). However, more patients, whose indication for cardiac catheterization was unstable angina, experienced events $(\mathrm{p}=0.03$, relative risk of $5.25,95 \%$ confidence interval $=1.47-18.70$ ). In addition, in the multivariate analysis of logistic regression, only unstable angina contributed independently to a higher risk of events $[\mathrm{p}=0.02$, odds ratio $(\mathrm{OR})$ of $8.43,95 \% \mathrm{CI}$ $=1.37-51.7]$.

\begin{tabular}{|c|c|c|c|c|}
\hline & All & $\begin{array}{l}\text { With events } \\
\qquad(n=7)\end{array}$ & $\begin{array}{l}\text { No events } \\
\quad(\mathrm{n}=48)\end{array}$ & $\mathrm{p}^{*}$ \\
\hline Age (years) & $61 \pm 10$ & $58 \pm 9$ & $61 \pm 10$ & 0.37 \\
\hline $\operatorname{Sex}(m / f)$ & $40 / 16$ & $5 / 2$ & $35 / 14$ & 1.0 \\
\hline $\begin{array}{l}\text { Risk factors for } \\
\text { atherosclerosis }\end{array}$ & 56 & 7 & 49 & 1.0 \\
\hline Risk factors for MRS & 42 & 5 & 37 & 1.0 \\
\hline $\operatorname{LMCD}(\%)$ & $73.5 \pm 16$ & $77 \pm 18$ & $73 \pm 16$ & 0.53 \\
\hline $\operatorname{LVSF}(\%)$ & $30 \pm 9$ & $30 \pm 9$ & $28 \pm 9$ & 0.58 \\
\hline UA & 7 & 3 & 4 & 0.03 \\
\hline \multicolumn{5}{|c|}{$\begin{array}{l}\text { * comparison between the patients who developed events and those who } \\
\text { did not; m- male; f- female; MRS- myocardial revascularization surgery; } \\
\text { LMCD- left main coronary disease; LVSF- left ventricular shortening fraction } \\
\text { on 2-dimensional echocardiography; UA- unstable angina. }\end{array}$} \\
\hline
\end{tabular}




\section{Discussion}

Despite the decrease in the incidence of complications during or after the first hours of cardiac catheterization in patients with left main coronary artery disease observed in the last years, this incidence still remains high when compared with that observed in other types of coronary lesion ${ }^{11}$. Houston et al ${ }^{13}$, analyzing the incidence of death during cardiac catheterization in 30,838 patients, observed that the deaths, except 1 , occurred in patients with left main coronary artery disease or with multiarterial lesions. Therefore, cardiac catheterization in patients with left main coronary artery disease has a high risk of complications during the procedure or within the first hours following it. After these first hours, however, little is known about the risk of events in these patients.

Based on the evidence of the benefit of the surgical treatment over the clinical treatment in patients with left main coronary artery disease $\geq 50 \%$, the notion that these patients should undergo urgent surgery has spread among clinical cardiologists and cardiac surgeons ${ }^{6}$. However, according to the results of the VACS study ${ }^{5}$, the benefit of the surgical treatment only becomes apparent from the third postoperative month on. In addition, according to the conclusion of the study by Maziak et $\mathrm{al}^{6}$ involving 281 patients with left main coronary artery disease waiting for myocardial revascularization surgery, a select group of these patients could wait for surgery with a low risk of complications. In this study, the authors emphasize that the surgery should be performed early (in the first 10 days following catheterization) in patients with severe symptoms or recent acute myocardial infarction. However, they did not study the factors that independently influenced the development of the events.
In our study, based on the observation of patients consecutively undergoing cardiac catheterization for the diagnosis of coronary artery disease, no patient with left main coronary artery disease had any complications during or within the first hours after the procedure. However, while waiting for surgery, 7 patients experienced cardiac events (acute myocardial infarction) in the first 60 days after catheterization. We also observed that the risk was 5 times greater in the patients whose indication for the examination was unstable angina, although stabilized. The patients with acute ischemic syndrome are known to be at a greater risk for developing cardiac events, mainly within the first 30 days of the disease ${ }^{14}$. However, it has not yet been established that the increased risk is determined by the coronary anatomy, but by a series of electrocardiographic and clinical factors, such as serum markers of thrombosis with embolization and myocardial necrosis and markers of an inflammatory process ${ }^{14-19}$. No other clinical, electrocardiographic, echocardiographic, or angiographic factor related to a greater risk for events has been found (tab. I).

Because this was a retrospective study, we could not adequately approach, especially in unstable angina, all the clinical, electrocardiographic, and laboratory parameters that could somehow influence the development of cardiac events. In addition, the small number of patients limited the statistical power of the study. We propose that new studies with a greater number of patients should be carried out, aiming at obtaining a higher statistical power for more definitive conclusions.

In conclusion, unstable angina in patients with left main coronary artery disease indicates a high risk for cardiac events, and, therefore, emergency surgery is recommended in these cases.

\section{References}

1. Conley MJ, Ely RL, Kisslo J, Lee KL, McNeer FM, Rosati RA. The prognostic spectrum of left main stenosis. Circulation 1979; 57: 947-52.

2. Takaro T, Pifarre R, Fish R. Left main coronary artery disease. Prog Cardiovasc Dis 1985; 28: 229-34.

3. Eagle KA, Guyton RA, Davidoff R, et al. ACC/AHA guidelines for coronary artery bypass surgery: executive summary and recommendations; a report of the American College of Cardiology/American Heart Association Task Force on Practice Guidelines (Committee to revise the 1991 Guidelines for Coronary Artery Bypass Graft Surgery). Circulation 1999; 100: 1464-80.

4. Caracciolo EA, Davis KB, Sopko G, et al for the CASS investigators. Comparison of surgical and medical group survival in patients with left main coronary artery disease: long-term CASS experience. Circulation 1995; 91: 2325-34.

5. Takaro T, Peduzzi P, Detre KA, et al. Survival in subgroups of patients with left main coronary artery disease. Veterans Administration Cooperative Study of Surgery for Coronary Arterial Occlusive Disease. Circulation 1982; 66: 14-22.

6. Maziak DE, Rao V, Christakis GT, et al. Can patients with left main stenosis wait for coronary artery bypass grafting? Ann Thorac Surg 1996; 61: 552-7.

7. Sones Jr FM, Shirley E. Cinecoronary arteriography. Mod Conceps Cardiovasc Dis 1962; 31: 735-8.

8. Judkins MP. Selective coronary arteriography: a percutaneous transfemoral technique. Radiology 1967; 89: 815-24.

9. Gordon RP, Abrams C, Gash AK, Carabello BA. Pericatheterization risk factors in left main coronary artery stenosis. Am J Cardiol 1987; 59: 1080-3.

10. Ko JK, Nishimura RA, Holmes DR, Bailey KR. Predictors of early mortality in patients with angiographycally documented left main coronary artery disease. Cathet Cardiovasc Diag 1991; 24: 84-7.

11. Pereira VJ, Carvalho ACC, Alves CMR, Resende ES, Souza JAM, Hermann JL. Complicações do estudo cinecoronariográfico em portadores de lesão do tronco da artéria coronária esquerda. Rev Brasil Cardiol Inv 1996; 4: 24-7.

12. Braunwald E. Unstable angina: a classification. Circulation 1989; 80: 410-4.

13. Houston BC, Higgins ZA, Beulands DS. Death in catheterization laboratory. Can Med Associat J 1993; 14: 165-9.

14. Holmvang L, Lüscher MS, Clemmensen P, Thygesen K, Grande P, and the TRIM Study Group. Very early risk stratification using combined ECG and biochemical assessment in patients with unstable coronary artery disease (a thrombin inhibition in myocardial ischemia [TRIM] substudy). Circulation 1998; 98: 2004-9.

15. Antman EM, Cohen M, Bernink PJL, et al. The TIMI risk score for unstable angina/non-ST elevation MI: a method for prognostication and therapeutic decision making. JAMA 2000; 284: 835-42.

16. Hamm CW, Braunwald E. A classification of unstable angina revisited Circulation 2000; 102: 118-22.

17. Antman EM, Fox KM. Guidelines for the diagnosis and management of unstable angina and non-Q-wave myocardial infarction: proposed revisions. Am Heart J 2000; 139: 461-75.

18. Lindahl B, Toss H, Siegbahn A, Venge P, Wallentin L, for the FRISC Study Group? N Engl J Med 2000; 343: 1139-47.

19. Kaul P, Chang W, Harrington RA, et al, for the PARAGON-A and GUSTO-IIB Investigators. Prognostic value of ST-segment depression in acute coronary syndromes: insights from PARAGON-A applied to GUSTO-IIB. J Am Coll Cardiol 2001; 38: 64-71. 